\title{
Innovative airway management for peritonsillar abscess
}

\author{
[Contrôle novateur des voies aériennes dans un cas de phlegmon amygdalien]
}

Michael Beriault MD, ${ }^{*}$ Jennifer Green MD, ${ }^{*}$ Anita Hui MD $\dagger$

Purpose: To describe innovative airway management in an adult with a peritonsillar abscess (quinsy) located atypically in the inferior pole of the palatine tonsil.

Clinical features: A 25-yr-old male was admitted for surgical drainage of a left-sided, inferior pole peritonsillar abscess. Previous attempts at intraoral needle and scalpel drainage with topical anesthesia in the emergency department had failed. He had an interdental distance of $1.5 \mathrm{~cm}$ and computed tomography imaging showed narrowing of the airway diameter to $8 \mathrm{~mm}$ and lateral displacement of the epiglottis. He gargled $10 \mathrm{~mL} 0.5 \%$ lidocaine in the sitting position. We advanced a 3.I-mm pediatric fibreoptic bronchoscope (FOB) through an orally inserted nasopharyngeal airway to identify the glottis and sprayed $0.5 \%$ lidocaine onto the airway mucosa. We replaced the airway with a reinforced $6.5-\mathrm{mm}$ internal diameter tracheal tube (TT), advanced the FOB through it until its tip was just above the carina, and then advanced the TT into the trachea. After iv induction of general anesthesia, the surgeon performed a tonsillectomy and drained the neck abscess. Postoperative direct laryngoscopy revealed a markedly improved airway lumen and tracheal extubation over a Cook Airway Exchange Catheter $^{\mathrm{TM}}$ was uneventful. The patient was stable in the recovery room, and was discharged on the third postoperative day.

Conclusion: We present an innovative technique of fibreoptic intubation in an awake patient with an inferior pole peritonsillar abscess.

Objectif: Décrire une méthode novatrice de contrôle des voies aériennes dans un cas de phlegmon amygdalien anormalement logé au pôle inférieur de l'amygdale palatine.

Éléments cliniques : Un homme de 25 ans a été admis à l'hôpital pour le drainage chirurgical d'un phlegmon amygdalien au pôle inférieur du côté gauche. Les drainages tentés auparavant par voie orale sous anesthésie topique réalisée à l'urgence avaient échoué. La distance interdentale était de $1,5 \mathrm{~cm}$ et la tomodensitométrie a montré un rétrécissement du diamètre des voies aériennes à $8 \mathrm{~mm}$ et un déplacement latéral de l'épiglotte. Le patient s'est gargarisé en position assise avec $10 \mathrm{~mL}$ de lidocaïne à $0,5 \%$. Un fibroscope bronchique pédiatrique de $3,1 \mathrm{~mm}$ (FOB) a été introduit au travers d'une sonde nasopharyngienne insérée dans la bouche pour repérer la glotte et pulvériser de la lidocaïne à 0,5\% sur la muqueuse des voies aériennes. Un tube endotrachéal (TE) renforcé de diamètre interne de 6,5 $\mathrm{mm}$ a remplacé la sonde oropharyngée. Le FOB a été poussé à l'intérieur du TE jusqu'à ce que sa pointe soit juste au-dessus de la carène et le TE avancé dans la trachée. Après l'induction iv de l'anesthésie générale, le chirurgien a procédé à l'amygdalectomie et drainé l'abcès du cou. La laryngoscopie directe postopératoire a révélé une lumière très améliorée des voies aériennes et l'extubation endotrachéale en laissant en place une bougie d'échange Cook Airway Exchange Catheter ${ }^{\mathrm{TM}}$ s'est déroulée sans incident. À la salle de réveil, l'état du patient était stable et il a quitté l'hôpital au troisième jour postopératoire.

Conclusion: Nous avons présenté une technique novatrice d'intubation fibroscopique chez un patient éveillé qui présentait un phlegmon au pôle inférieur de l'amygdale.

$\mathrm{P}$ ERITONSILLAR abscess (PTA) or quinsy presents a difficult airway problem. The abscess limits conventional access to the airway, distorts it, and poses the additional risk of aspiration of pus. The airway is the immediate issue, but anatomical spread of the infection may cause mediastinitis, pericarditis, and invasion of the carotid sheath. In the presence of a recognized difficult airway, the collected wisdom of the American Society of Anesthesiologists (ASA) Difficult Airway Algorithm ${ }^{1}$ might best be summarized as: "Do as much as you

From the Departments of Anesthesiology* and Surgery, † Foothills Medical Center, University of Calgary, Calgary, Alberta, Canada. Address correspondence to: Dr. Michael Beriault, Department of Anesthesiology, Foothills Medical Center, 1403-29 ${ }^{\text {th }}$ St. N.W., Calgary

Alberta T2N 2T9, Canada. Phone: 403-944-1430; Fax: 403-944-2425; E-mail: beriaul@telusplanet.net Accepted for publication May 3, 2005.

Revision accepted July 27, 2005. 


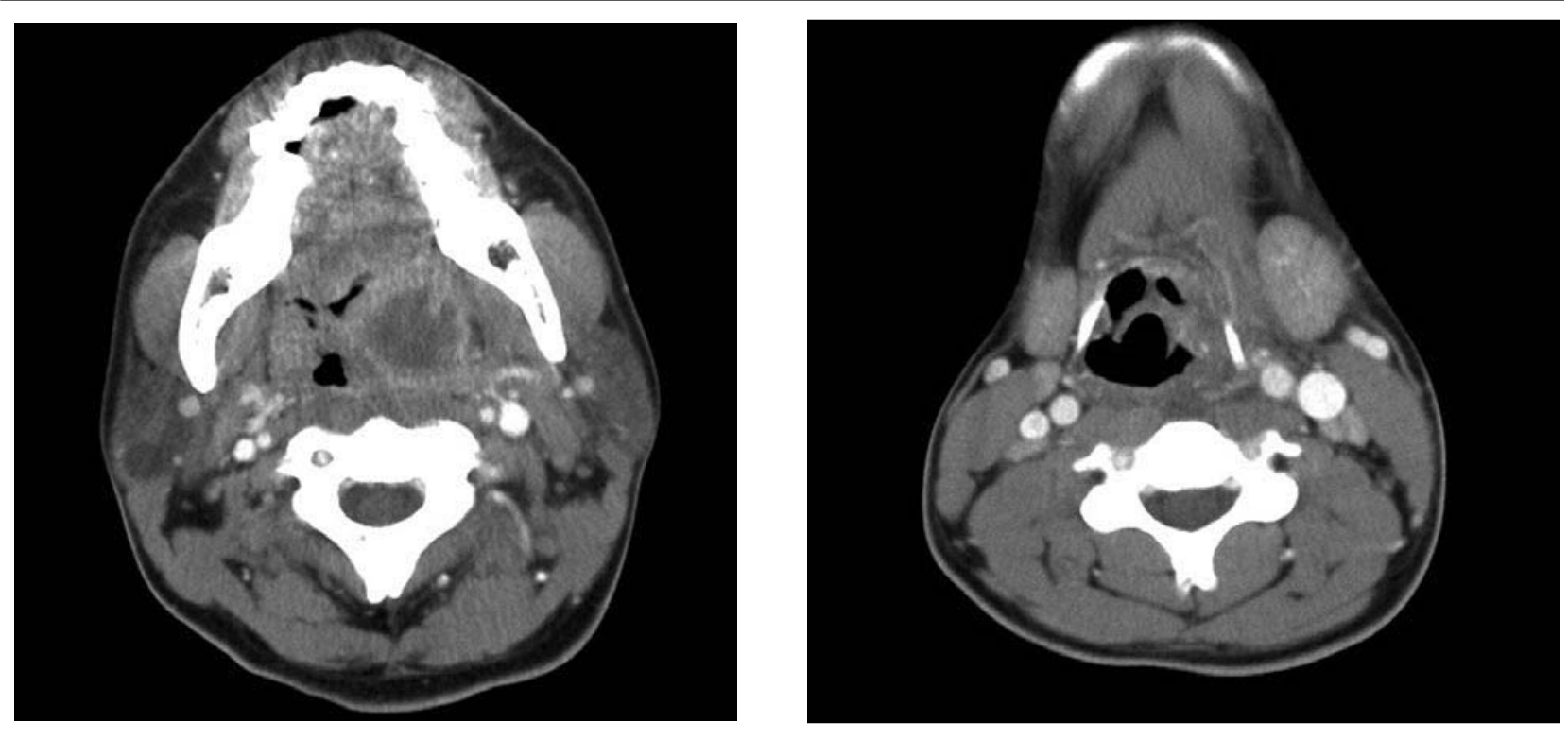

FIGURES 1 and 2 The left-sided peritonsillar abscess can be seen compressing the upper airway to a width of $8 \mathrm{~mm}$ and extending down to the $\mathrm{L}$ pyriform fossa and displacing the glottis from the midline.

can under direct vision with the patient awake". We describe an innovative approach to this airway problem, respecting fundamental difficult airway management principles.

\section{Case report}

A 25-yr-old healthy male was admitted for surgical drainage of a left sided, inferior pole PTA after previous attempts at intraoral needle and scalpel drainage under local anesthesia in the emergency department had failed. His computed tomography (CT) scan showed a PTA, encroaching upon the airway at the left tonsillar bed and reducing the airway lumen to 8 $\mathrm{mm}$ (Figure 1). The abscess extended into the pyriform fossa and displaced the epiglottis away from the midline (Figure 2). The patient demonstrated a muffled voice, trismus, drooling, an interdental distance of $1.5 \mathrm{~cm}$, and normal neck mobility. He preferred to sit. We enlisted his cooperation to secure his airway under local anesthesia either by tracheal intubation or tracheostomy prior to induction of general anesthesia.

With provision for a surgical airway immediately available, we affixed routine monitors and administered oxygen via nasal prongs. Nasal vasoconstrictors had been previously given. We kept the patient in the sitting position and gave $200 \mu \mathrm{g}$ iv glycopyrrolate. Although he could not swallow, he was able to gargle $10 \mathrm{~mL}$ of $0.5 \%$ lidocaine instilled through an
18 gauge $i v$ cannula advanced through the right naris. Next we inserted a Portex ${ }^{\mathrm{TM}} 6.0-\mathrm{mm}$ nasopharyngeal airway lubricated with lidocaine gel orally on the right side and guided it toward the lumen of the airway as demonstrated by his CT imaging. We then advanced a 3.1-mm LF-DP Olympus ${ }^{\mathrm{TM}}$ pediatric fibreoptic bronchoscope (FOB) through the airway and into the patient's pharynx. After identifying the glottis, we passed a \#20 Portex ${ }^{\mathrm{TM}}$ multi-orifice epidural catheter through the suction port of the FOB and gently sprayed additional $0.5 \%$ lidocaine onto the airway mucosa. We then substituted a Mallinckrodt ${ }^{\mathrm{TM}}$ reinforced $6.5-\mathrm{mm}$ tracheal tube (TT) for the nasal airway and inserted a bite block between the patient's teeth. We passed the FOB through the TT, entered the upper airway, and again used the epidural catheter to apply topical lidocaine to the vocal cords and upper trachea. The tip of the FOB was then positioned above the carina and the TT advanced over the FOB and confirmed to be in the trachea. After $i v$ induction of general anesthesia, the surgeon performed a tonsillectomy and drained the neck abscess. Postoperatively, we performed a direct laryngoscopy, which revealed a markedly improved airway lumen. We then extubated the trachea over a Cook Airway Exchange Catheter ${ }^{\mathrm{TM}}$ CAE-11.0-83DLT. The patient was stable in the recovery room and discharged on the third postoperative day. 


\section{Discussion}

Although FOB is considered the gold standard for difficult intubation, it is not always successful on the first attempt. ${ }^{2}$ To enhance our chance of initial success, several points were addressed. We kept the patient in the sitting position, reducing the distortion of the airway which occurs in the recumbent position, and allowing gravity to bias the direction of the FOB, epidural catheter, local anesthetic application and eventually the TT to the aperture of the vocal cords. We intentionally selected a $6.5-\mathrm{mm}$ internal diameter reinforced TT for several reasons and with one caveat. The narrowest portion of the upper airway measured $8 \mathrm{~mm}$ by CT scanning, which meant the external diameter of a $6.5-\mathrm{mm}$ internal diameter TT would just pass without disrupting the abscess. The relative size of the internal diameter of the TT to the external diameter of the FOB is also important. The diameter of the TT must allow the TT to glide down the FOB easily. The TT will follow the path of the FOB and its bevel is less likely to impinge the rim of the glottis if there is a minimal gap between the diameters of the FOB and TT. ${ }^{3}$ By employing a reinforced TT, we hoped the additional flexibility afforded by the spiral wire embedded in the wall of the TT would further reduce the chance of the bevel of the TT hanging up as we advanced it through the larynx. ${ }^{4}$ We used a bite block (gauze wrapped and taped in a wedge) to protect the TT from the patient inadvertently biting and permanently deforming the lumen. ${ }^{5}$

Fagan et al..$^{6}$ reported a prospective study of 15 patients with PTA, none located in the uncommon inferior pole position. Their airway management strategies were predicated on the simple measure of draining the tonsillar abscess prior to definitive surgery. Patients then underwent an iv $(n=47)$ or inhalational $(n=3)$ induction prior to tracheal intubation. This important measure of drainage under local anesthesia is time-honoured advice ${ }^{7}$ but may be limited by patient cooperation or as illustrated in our case, the unfavourable and less common location of the abscess in the inferior pole of the palatine tonsil. ${ }^{8}$ Faced with an undrained PTA abscess and clinical and radiological evidence of severe upper airway compromise, we elected to secure this cooperative patient's airway prior to inducing general anesthesia. Because the PTA affected the left side of the neck, it obscured the anatomic landmarks for selective nerve blocks to anesthetize the airway.

We planned an intubation with an oral TT. We kept the patient sitting as this was key to the success of the airway plan. Although the patient's nasopharynx had been prepared with topical vasoconstrictors, we favoured an oropharyngeal route to avoid adding potential nasal hemorrhage to an already difficult airway. We dripped lidocaine through the nose so that it could be gargled without requiring the patient to swallow. We anticipated the soft nasopharyngeal airway and epidural catheter would be less likely to puncture the abscess and flood the partially anesthetized airway with pus. We directed the nasopharyngeal airway through the right side of the mouth and advanced it gently toward the lumen of the airway as demonstrated on the CT scan. The pediatric FOB was passed through it, and when the patient's glottis identified, we advanced an epidural catheter through the suction channel to deliver more topical local anesthetic. ${ }^{9}$

Successful tracheal placement of the TT was confirmed by direct visualization of the carina below the tip of the TT prior to induction of general anesthesia. Alternatively, the TT could have been connected to an $\mathrm{ETCO}_{2}$ detector and $\mathrm{CO}_{2}$ demonstrated with ventilation. Seeing the tip of the TT above the carina ensures a tracheal seating rather than a mainstem bronchus placement of the TT. Bronchial intubation cannot be excluded by simply detecting expired $\mathrm{CO}_{2}$. Finally, we planned for the extubation of a difficult airway by direct laryngoscopy to confirm the successful decompression of the airway, and then extubating the trachea over a jetting exchange catheter when the patient was awake.

Published experience with securing the airway in awake patients with undrained PTAs, especially those uncommonly located in the inferior pole of the palatine tonsil, is sparse. Peer reviewed case reports of airway management which respect the guidelines of the ASA Difficult Airway Algorithm, and give practical descriptions of techniques and devices to manage the airway in this infrequent condition may be of use to the practicing anesthesiologist.

\section{Acknowledgements}

We appreciate the criticisms and suggestions offered by Dr. J.R. Maltby in reviewing the manuscript. Dr. C. Doig confirmed that the local ethical guidelines for protection of personal heath information and privacy were respected. The clinical assistance of respiratory therapist Jo-Dean Jahns in the conduct of the airway management for this case is also acknowledged. Thank you to V. Repper for patient secretarial support.

\section{References}

1 Stone DJ, Gal TJ. Airway management. In: Miller RD (Ed.). Anesthesia 5th ed. New York: Churchill Livingstone Inc.; 2000: 1414-51.

2 Manecke GR Jr, Marghoob S, Finzel KC, Madoff DC, 
Quijano IH, Poppers PJ. Catastrophic caudad spread of a peritonsillar abscess: a case report. Anesthesiology 1999; 91: 1956-8.

3 Maktabi MA, Hoffman H, Funk G, From RP.

Laryngeal trauma during awake fiberoptic intubation. Anesth Analg 2002; 95: 1112-4.

4 Brull SJ, Wiklund R, Ferris C, Connelly NR, Ehrenwerth J, Silverman DG. Facilitation of fiberoptic orotracheal intubation with a flexible tracheal tube. Anesth Analg 1994; 78: 746-8.

5 Dorsch JA, Dorsch SE. Tracheal tubes. In: Dorsch JA (Ed.). Understanding Anesthesia Equipment, 4th ed. Baltimore: Williams \& Wilkins Co.; 1998: 557-675.

6 Fagan JJ, James MF. A prospective study of anaesthesia for quinsy tonsillectomy. Anaesthesia 1995; 50: 783-5.

7 Baines $D$. Anaesthesia for quinsy (Letter). Anaesthesia 2004; 59: 198-9.

8 Licameli GR, Grillone GA. Inferior pole peritonsillar abscess. Otolaryngol Head Neck Surg 1998; 118 : 95-9.

9 Long TR, Wass CT. An alternative to transtracheal injection of fiberoptic intubation in awake patients: a novel noninvasive technique using a standard multiorifice epidural catheter through the bronchoscope suction port (Letter). Anesthesiology 2004; 101: 1253. 